\title{
三元共晶温度以上で強磁場熱処理した $\mathrm{Nd}-\mathrm{Fe}-\mathrm{B}$ 系焼結磁石の低温熱処理と減磁曲線
}

\author{
秋 屋 貴 博1 \\ 佐藤文隆 ${ }^{2}$ \\ 佐川眞 人 $^{3}$ \\ 高橋弘 紀 4 \\ 1東北大学未来科学技術共同研究センター
${ }^{2}$ 東北大学大学院工学研究科応用物理学専攻
${ }^{3}$ インターメタリックス株式会社
${ }^{4}$ 東北大学金属材料研究所
${ }^{5}$ 山形大学大学院理工学研究科数物学分野
}

宇 根 康 裕 ${ }^{3}$

加藤 宏 朗 1,5

J. Japan Inst. Metals, Vol. 75, No. 4 (2011), pp. 193-197 (C) 2011 The Japan Institute of Metals

\section{Low-Temperature Annealing and Demagnetization Curves in Sintered Nd-Fe-B Magnets High-Field Annealed at Temperatures above Ternary-Eutectic Point}

Takahiro Akiya ${ }^{1}$, Fumitaka Sato ${ }^{2}$, Yasuhiro Une ${ }^{3}$,

Masato Sagawa ${ }^{3}$, Kohki Takahashi ${ }^{4}$ and Hiroaki Kato ${ }^{1,5}$

\author{
${ }^{1}$ New Industry Creation Hatchery Center, Tohoku University, Sendai, 980-8579 \\ ${ }^{2}$ Department of Applied Physics, Graduate School of Engineering, Tohoku University, Sendai 980-8579 \\ ${ }^{3}$ Intermetallics Co., Ltd., Kyoto 615-8245 \\ ${ }^{4}$ Institute for Materials Research, Tohoku University, Sendai, 980-8577 \\ ${ }^{5}$ Department of Applied Mathematics and Physics, Graduate School of Science and Engineering, Yamagata University, \\ Yonezawa 992-8510
}

Effect of magnetic-field direction applied during annealing at $800^{\circ} \mathrm{C}$ on the demagnetization process was investigated systematically in sintered $\mathrm{Nd}-\mathrm{Fe}-\mathrm{B}$ magnets. We observed a stepwise decrease in the demagnetization curve when the perpendicular field was applied during the $800^{\circ} \mathrm{C}$ annealing, which suggests an existence of soft magnetic grains. We then annealed this sample in zero field successively from $T_{\mathrm{a}}=400^{\circ} \mathrm{C}$ to $720^{\circ} \mathrm{C}$ with the temperature increment of $10^{\circ} \mathrm{C}$, and traced a change in demagnetization curves. The volume fraction $V_{\text {soft }}$ of the soft magnetic grains was estimated from the step width of the demagnetization curves. The $V_{\text {soft }}$ value showed a maximum around $T_{\mathrm{a}}=500^{\circ} \mathrm{C}$ with $V_{\text {soft }}=25 \%$, and decreased rapidly with increasing $T_{\mathrm{a}}$. The coercivity versus $T_{\mathrm{a}}$ plot exhibited a similar tendency to that of $V_{\text {soft }}$ versus $T_{\mathrm{a}}$ plot. Origin of such soft magnetic grains is considered to be a precipitation of perpendicularly-aligned $\mathrm{Nd}_{2} \mathrm{Fe}_{14} \mathrm{~B}$ small particles in the grain boundary, which would act as a nucleation site on the large $\mathrm{Nd}_{2} \mathrm{Fe}_{14} \mathrm{~B}$ host matrix. These results suggest that the magnetic coupling between $\mathrm{Nd}_{2} \mathrm{Fe}_{14} \mathrm{~B}$ grains is one of the important factors to understand the coercivity mechanism in sintered $\mathrm{Nd}-\mathrm{Fe}-\mathrm{B}$ magnets.

(Received October 21, 2010; Accepted December 20, 2010)

Keywords: sintered neodymium-iron-boron magnet, coercivity, high magnetic field processing

\section{1.はじめに}

$\mathrm{Nd}-\mathrm{Fe}-\mathrm{B}$ 系焼結磁石は, 現在世界最強の希土類磁石であ り，その用途は電気自動車の駆動用モーターなどへ拡大しつ つある。ところが, 高負荷条件下では $200^{\circ} \mathrm{C}$ 近くまで磁石 の温度が上昇するため, 不可逆的な熱減磁が起こることが問 題となっている. その解決のためには, 保磁力を上昇させる ことが有効であり, 現在様々な指針に基づいた多くの研究が 行われている.

$\mathrm{Nd}-\mathrm{Fe}-\mathrm{B}$ 系焼結磁石の保磁力を上昇させるための手段と しては, Dyなどの異方性磁場を高める効果のある元素を用
いる方法 1,2$), \mathrm{Cu}$ などを添加して粒界相の特性を変化させる 方法 ${ }^{3,4)}$, 熱処理パターンの最適化5)などが提案され, 実際に 工業プロセスに応用されている，一方，Vial らは作製プロ セスの最終段階で行われる低温熱処理によって, 保磁力は劇 的に上昇するとともに, 数 $\mu \mathrm{m}$ 径の $\mathrm{Nd}_{2} \mathrm{Fe}_{14} \mathrm{~B}$ 主相表面に, 連続的な Nd-rich 粒界相が形成されることを報告した6). た最近の報告から, 主相表面に連続的な粒界構造が形成され ることが高保磁力発現のための必要条件であることは多くの 研究によって認められており, 現在理想的な微細構造の解明 と, 如何に理想構造を形成せしめるかが課題となっている.

我々は, $\mathrm{Nd}-\mathrm{Fe}-\mathrm{B}$ 系焼結磁石中の粒界構造に変化をもた らし, 高保磁力が得られる微細構造を明らかにすることを目 
的として, 強磁場プロセッシングの可能性について研究を行 っている。これまでに， $\mathrm{Nd}-\mathrm{Fe}-\mathrm{B}$ 系焼結磁石に $\mathrm{Cu}$ を添加 することで， $475^{\circ} \mathrm{C}$ 抢よび $550^{\circ} \mathrm{C}$ に融点をもつ何らかの物質 が形成されることをDSCによる熱分析で確認し，それらの 温度近傍で強磁場中熱処理を施した場合に保磁力が上昇する ことを示してきた7,8). その機構については，強磁場中熱処 理によって粒界相に存在する物質の磁場配向が起こり，通常 と異なる微細構造が形成されたためであると考えている。一 方, $\mathrm{Nd}_{2} \mathrm{Fe}_{14} \mathrm{~B}$ は, Curie 温度以上の常磁性状態でもその $\mathrm{Nd}$ の結晶場に起因する磁化率の異方性を有していることから， $1000^{\circ} \mathrm{C}$ 以上の高温でも共融状態にある $\mathrm{Nd}-\mathrm{Cu}$ 液相中で浮遊 している $\mathrm{Nd}_{2} \mathrm{Fe}_{14} \mathrm{~B}$ 粒子は，強磁場環境で配向することが報 告されている ${ }^{9)}$. すなわち, 三元共晶温度以上から強磁場中 で冷却することで, 粒界に析出する $\mathrm{Nd}_{2} \mathrm{Fe}_{14} \mathrm{~B}$ 相を配向でき る可能性がある。

そこで本論文では，三元共晶温度以上における強磁場熱処 理の効果, およびその後の低温熱処理による減磁曲線の变化 を明らかにすることを目的として行った以下，二つの実験結 果を示す。一つ目は $\mathrm{Nd}-\mathrm{Fe}-\mathrm{B}$ 系焼結磁石の三元共晶温度以 上で熱処理中に印加した，強磁場の方位の影響である．その 結果として, 試料の配向方向に対して垂直方向に強磁場を印 加した場合, 減磁曲線に低保磁力領域が現れることが示され る. 二つ目は，その低保磁力領域が現れた試料について， SSA 法10) (Single Successive Annealing 法)で熱処理温度に 対する保磁力や減磁曲線の形状の変遷を追跡した結果につい て述べる，特に，減磁曲線の形状の変化に着目し，低温熱処 理によって保磁力が変化する原因について考察する.

\section{2. 実 験 方 法}

実験に用いた $\mathrm{Nd}-\mathrm{Fe}-\mathrm{B}$ 系焼結磁石は, 焼結前の粉砕の工 程で主相の平均粒径を $1.4 \mu \mathrm{m}$ まで微細化し, 試験的に作製 されたものである。組成は，Dy およびCo を含まない， $\mathrm{Nd}_{32.48} \mathrm{Fe}_{\text {bal }} \mathrm{B}_{0.98} \mathrm{Cu}_{0.11} \mathrm{Al}_{0.24}(\operatorname{mass} \%$ ) である.なお， 今回の 熱処理にはバルブ付きの片封石英管を用いた。試料空間は一 旦 $1 \times 10^{-4} \mathrm{~Pa}$ まで真空引きを行った後, 熱伝導性を高める 目的で $10^{3} \mathrm{~Pa}(0.01$ 気圧 $)$ 程度まで純へリウムを導入した.

まず試料に, $8.0 \mathrm{MA} / \mathrm{m}$ の強磁場中で, $800^{\circ} \mathrm{C}$ で $120 \mathrm{~min}$ の熱処理を施した。磁場の方位は試料の配向方向に対し平 行，または垂直とした。磁場は $400^{\circ} \mathrm{C}$ まで冷却する間も印 加し続けた。

これらの試料について，減磁曲線の熱処理温度に対する変

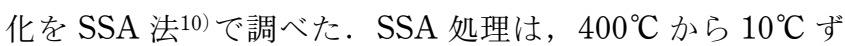
つ保持温度を上げながら, 最大 $720^{\circ} \mathrm{C}$ まで行った。各熱処 理温度での保持時間は $30 \mathrm{~min}$ とし，熱処理後は試料を $10^{3}$ $\mathrm{Pa}$ 程度のヘリウム雾囲気を保ったまま, 石英管を冷水中に 投入して冷却を行った。冷却速度はおよそ $100^{\circ} \mathrm{C} / \mathrm{min}$ であ る.なお，この繰り返し熱処理については，すべてゼロ磁場 中で行っている.

磁気測定には，東栄工業侏製パルス励磁型磁気特性測定装 置を用いた。印加したパルス磁場の最大值は $6.4 \mathrm{MA} / \mathrm{m}$ で ある。

\section{3. 結 果と考察}

\section{1 強磁場熱処理後の減磁曲線}

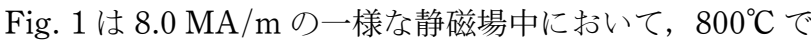
$120 \mathrm{~min}$, 強磁場熱処理と磁場中冷却を行った直後の試料の 減磁曲線である. 図中には, 試料の配向方向に対して磁場を 平行または垂直に印加したものとともに，磁場を加えなかっ た参照試料の結果も示した。磁場を試料の配向方向に平行に 印加した場合の減磁曲線は，参照試料とほぼ同等である。 方，磁場を配向方向に対して垂直方向に印加した場合では， 減磁曲線に明らかな磁化のステップ的減少が観測された。す なわち, 配向方向に対して垂直方向に磁場を印加しながら熱 処理および磁場中冷却を行った場合，何らかの理由で低保磁 力化が起こることを意味する.

強磁場プロセッシングによって引き起こされる現象の一つ として，強磁場中で液相から凝固抢よび析出する固相の形態 や結晶方位が変化することが報告されている11)。今回の場 合では, 三元共晶温度以上で強磁場中熱処理後, 同磁場中で 冷却することで，液相から凝固析出した $\mathrm{Nd}_{2} \mathrm{Fe}_{14} \mathrm{~B}$ 固相が， 数 $\mu \mathrm{m}$ サイズの主相表面で通常とは異なる表面構造を形成し たことが考えられる。 まず，約 $670^{\circ} \mathrm{C}$ 以上でいくつかの $\mathrm{Nd}_{2}$ $\mathrm{Fe}_{14} \mathrm{~B}$ 相が関係した $\mathrm{Nd}-\mathrm{Fe}-\mathrm{B}$ 三元系の反応が報告されてい るが12)，一般的な焼結磁石と同様に本実験で用いている試 料は $\mathrm{Nd}$ が過剰な組成であることなどから，

$$
\mathrm{L} \rightleftarrows \mathrm{Nd}+\mathrm{Nd}_{2} \mathrm{Fe}_{14} \mathrm{~B}
$$

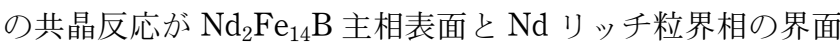
で起こっている。すなわち， $800^{\circ} \mathrm{C}$ で熱処理を行っていると きには， $\mathrm{Nd}_{2} \mathrm{Fe}_{14} \mathrm{~B}$ 相の表面は融解していると考えられる. その後, 強磁場中で冷却した際に析出した $\mathrm{Nd}_{2} \mathrm{Fe}_{14} \mathrm{~B}$ が磁場 方位に影響を受けたと考えられるが，これまでに粒界に微細

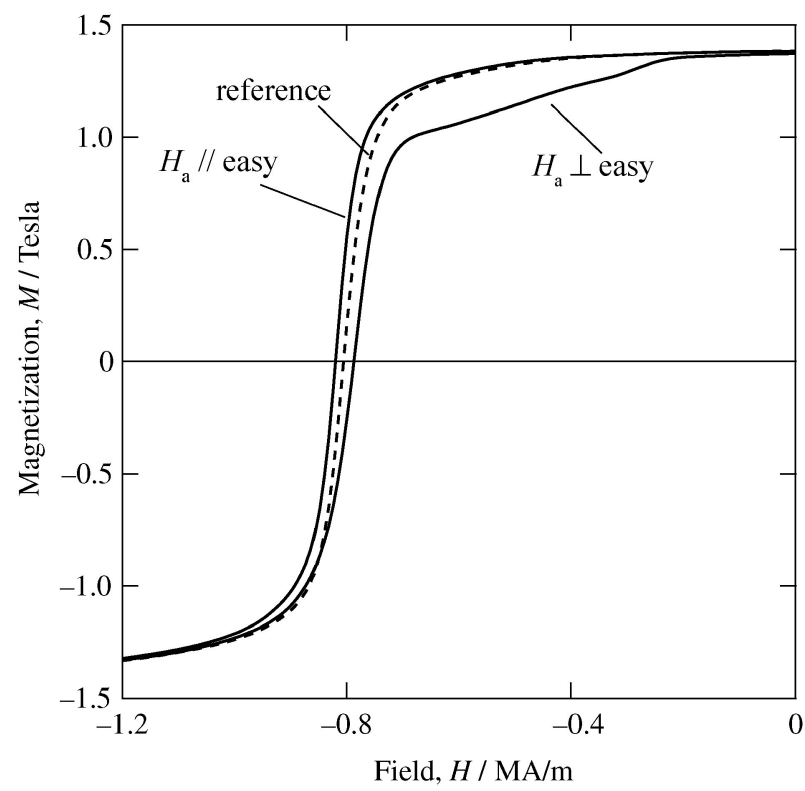

Fig. 1 Demagnetization curves for high-field-processed samples (solid lines) and control sample (dashed line) just after annealing at $800^{\circ} \mathrm{C}$. Applied field directions during the annealing are indicated in the figure. 
な $\mathrm{Nd}_{2} \mathrm{Fe}_{14} \mathrm{~B}$ 粒子が析出し，存在するという報告例はない, しかし, 強磁場中冷却時に主相表面で形成された複雑なナノ 構造が逆磁区の核生成サイトとなり，低保磁力化に寄与した ことは十分考えられる.ただし, 現段階では微細構造観察に よる証拠が得られていないため, 上記の仮説を述べるまでに 留めたい。

\section{2 減磁曲線の熱処理温度に対する変化}

Fig. 2 は, 垂直方向の磁場中で強磁場熱処理を施した試料 について, SSA 法を用いて得られた, 熱処理温度 $T_{\mathrm{a}}$ に対す る減磁曲線の変化をまとめたものである。また, SSA 法で 得られた保磁力の熱処理温度依存性を Fig. 3 に示した.な 打同図中には，次節で述べる，ソフト領域の体積分率も同時 に示されている.

$T_{\mathrm{a}}=400^{\circ} \mathrm{C}$ から熱処理温度を上げてゆくと, 保磁力は $T_{\mathrm{a}}$ $=440^{\circ} \mathrm{C}$ で極小值を示した. また, 減磁曲線に現れた磁化の ステップ的減少は, 熱処理温度の上昇に伴って徐々に明瞭に なった．なお，これまで SSA 処理によって調べた一般的な $\mathrm{Nd}-\mathrm{Fe}-\mathrm{B}$ 系焼結磁石の保磁力の熱処理温度依存性をみると, $T_{\mathrm{a}}=440^{\circ} \mathrm{C}$ 程度で熱処理することで極小值を示す 10$)$. 換言す れば, 低温熱処理による保磁力の上昇は $T_{\mathrm{a}}=440^{\circ} \mathrm{C}$ 程度か ら進行する。ただし DSCなどによる熱分析によって， $440^{\circ} \mathrm{C}$ 付近に熱異常は必ずしも観測されず，粒界における何 らかの液相の発生が誘因かどうかは不明である。をた, SSA 処理開始時の保磁力が, 本来の值に対して高かったために, $T_{\mathrm{a}}=400^{\circ} \mathrm{C}$ 付近で保磁力が減少していく機構と, 最適熱処理 温度に近づくことで保磁力が上昇していく機構の両者の兼ね 合いで, 保磁力の極小值が $T_{\mathrm{a}}=440^{\circ} \mathrm{C}$ 付近で観測されたと
いう可能性も払拭できない.

$T_{\mathrm{a}}=440 \sim 530^{\circ} \mathrm{C}$ の範囲では, 保磁力は単調に上昇した. 一方, 減磁曲線に現れたステップ的な磁化の減少は徐々に大 きく, 明瞭になっていき, $T_{\mathrm{a}}=480^{\circ} \mathrm{C}$ で高保磁力領域と低保 磁力領域の 2 領域に完全に分離した. 寸なわち, 低保磁力 領域が, はじめのうちは何らかの理由で保磁力を有していた が， $T_{\mathrm{a}}=480^{\circ} \mathrm{C}$ でほぼ保磁力を失う.このような熱処理温度 の上昇に伴う低保磁力領域の体積分率の振る舞いについて

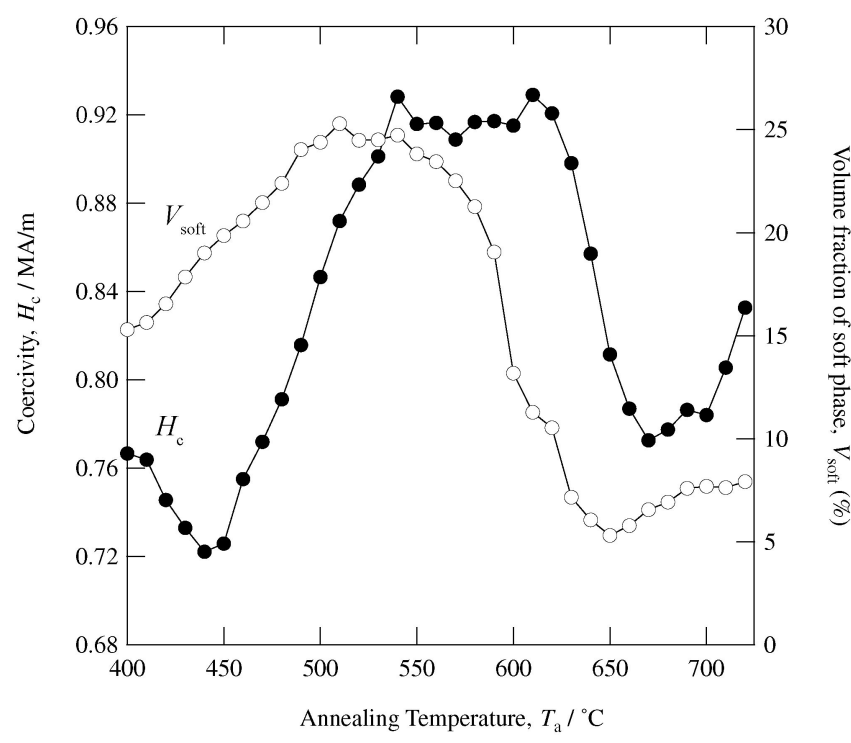

Fig. 3 Annealing-temperature dependence of coercivity, $H_{c}$ and volume fraction of soft phase, $V_{\text {soft }}$ derived from the demagnetization curves shown in Fig. 2.
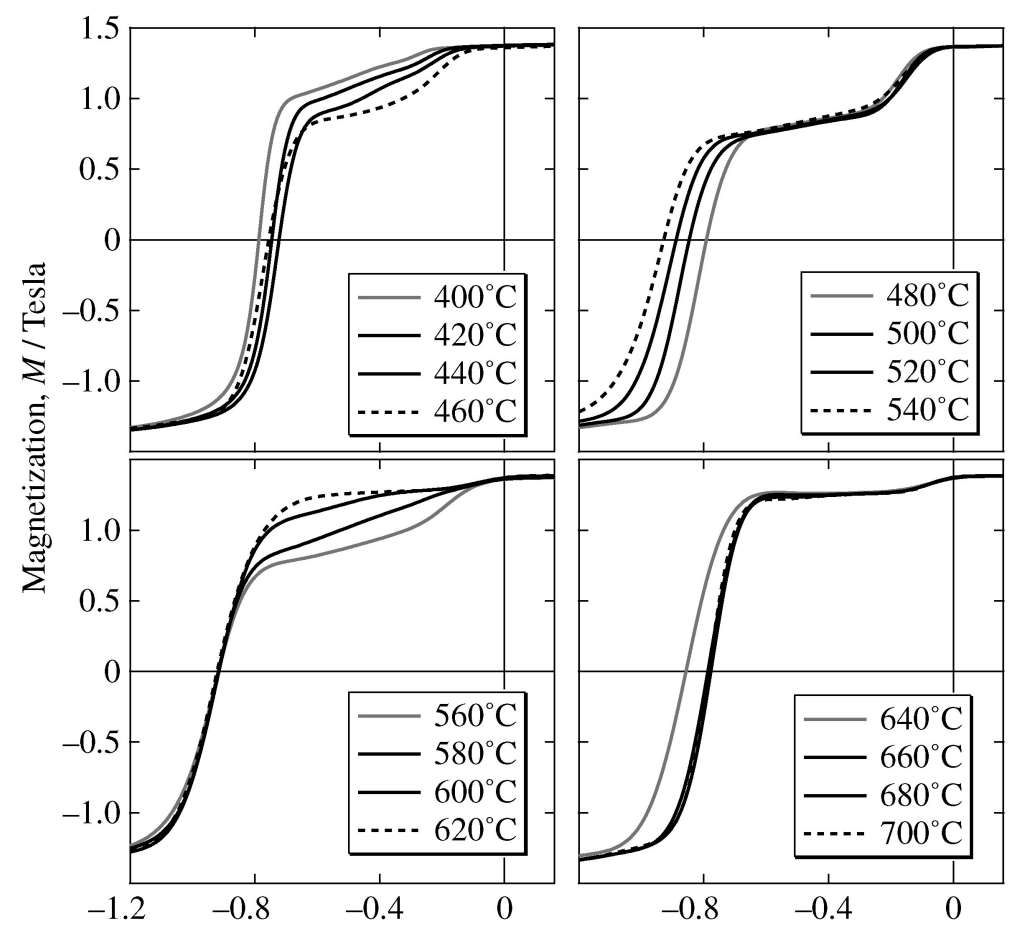

Field, $H / \mathrm{MA} / \mathrm{m}$

Fig. 2 Variation of demagnetization curves traced by single-successive annealing, SSA method for the sample annealed at $800^{\circ} \mathrm{C}$ in the perpendicular field. No field was applied during the SSA treatments. 
は，次節にて詳細に議論する。また， $T_{\mathrm{a}}=480 \sim 540^{\circ} \mathrm{C}$ まで は，低保磁力領域には変化が見られなかったが，高保磁力領 域のみが単に高磁場側ヘシフトした．すなわち，低保磁力領 域には変化が無いが, 高保磁力領域の平均的な保磁力は連続 的に上昇していくことを示唆する。ここで，低保磁力領域と 高保磁力領域が混在し, 明らかに分離している場合には, 減 磁曲線の第 2 象限で磁化がゼロとなる通常の保磁力はあま り意味を持たない。一方で，減磁曲線の分離を行い，高保磁 力領域のみの保磁力を求めることも可能である. そのような 場合, Fig. 3 に示した保磁力の值に比べ, 高保磁力領域の保 磁力は, $1 \times 10^{-2} \mathrm{MA} / \mathrm{m}$ 程度高い值となる.

$T_{\mathrm{a}}=540 \sim 620^{\circ} \mathrm{C}$ の範囲では, 高保磁力側の減磁曲線には 変化が見られないが，低保磁力成分である磁化のステップは 徐々に小さくなった，このことは，高保磁力領域の变化とは 独立して，低保磁力領域の高保磁力化が進行することを意味 している. さらに $T_{\mathrm{a}}=630^{\circ} \mathrm{C}$ 以上では, 全磁化の $5 \%$ 程度に 相当する低保磁力成分が残っているが，減磁曲線の角型性は 保ちつつ, 保磁力は徐々に低下した。 また， $\mathrm{Nd}-\mathrm{Fe}-\mathrm{B}$ 系三 元共晶温度より高い $670^{\circ} \mathrm{C}$ 以上で僅かに保磁力が上昇する ことも確認した. なお, 最終的に残った低保磁力領域は, 繰 り返し熱処理で磁石表面に形成された酸化物相などによるも のではなく, 試料内部に存在していることを確認している.

\section{3 熱処理温度に対する低保磁力領域の体積分率の変化}

減磁曲線に現れた, 保磁力が低下した低保磁力領域の体積 分率 $V_{\text {soft }}$ を熱処理温度に対してプロットした結果をFig. 3 に示す。ここで $V_{\text {soft }}$ は, 減磁曲線を磁場で一階微分した $\mathrm{d} M / \mathrm{d} H$ 曲線 (Fig. 4 参照)を用い，ピークを数值的に分離し て算出した.

まず $T_{\mathrm{a}}=400 \sim 500^{\circ} \mathrm{C}$ の範囲では, $V_{\text {soft }}$ は熱処理温度の上 昇に伴って単調に増加し, 最大で $25 \%$ 程度が保磁力を失っ た低保磁力領域となっている. 次に, $T_{\mathrm{a}}=500 \sim 550^{\circ} \mathrm{C}$ の範 囲では $V_{\text {soft }}$ 值には变化は見られなかったが， $T_{\mathrm{a}}=550^{\circ} \mathrm{C}$ 以 上で，減磁曲線の磁化のステップ的減少が消失することに伴

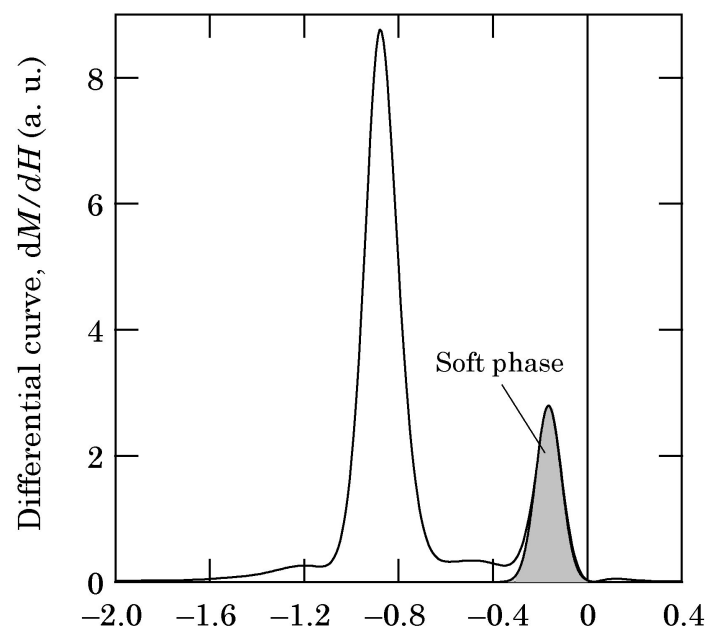

Field, $H / \mathrm{MA} / \mathrm{m}$

Fig. $4 \mathrm{~d} M / \mathrm{d} H$ curve for typical demagnetization curve. This curve is used to estimate volume fraction of soft phase, $V_{\text {soff }}$.
う急激な $V_{\text {soft }}$ の低下が観測された。 その後 $V_{\text {soft }}$ は $T_{\mathrm{a}}=$ $650^{\circ} \mathrm{C}$ で極小を示し，それ以上の高温ではわずかに増加後ほ ぼ一定值を示した。このような $V_{\text {soft }}$ と保磁力の熱処理温度 上昇に対する変化を説明するために，高保磁力粒子と低保磁 力粒子が混在しているモデルを考えた．以降，両者をハード 粒子，ソフト粒子とそれぞれ呼ぶことにする.

モデルでは，磁石粒子間に単純なフェロ的磁気結合が働い ていると仮定する。この場合，ハード粒子とソフト粒子の保 磁力は, 磁気的結合が強いほど平均化されることが予想でき

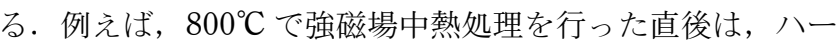
ド粒子とソフト粒子は磁気的に強く結合しているため, ソフ 卜粒子の磁化反転はハード粒子に妨げられ，幾分の保磁力を 持つ.しかし，ソフト粒子はハード粒子の保磁力を下げるよ うに寄与するため，平均的には比較的低い保磁力を示す.

まず $T_{\mathrm{a}}=400 \sim 500^{\circ} \mathrm{C}$ の範囲では，熱処理温度の上昇に伴 って各主相粒子が磁気的に分離されていき，ソフト粒子が ハード粒子から孤立していくために， $V_{\text {soft }}$ が上昇してい く．それに伴い， $T_{\mathrm{a}}=440^{\circ} \mathrm{C}$ 以上ではハード粒子同士も磁気 的に孤立していくために, 平均的な保磁力も上昇していく. つまり， $T_{\mathrm{a}}=400 \sim 500^{\circ} \mathrm{C}$ の範囲では，主相粒子同士が互い に磁気的に孤立していくと考えれば説明できる。ここで，な ぜ粒子間の磁気的結合性が熱処理温度に影響されるのか，と いう疑問が生ずる，スピン交換結合が磁気的結合性の主因で あるとすれば，主相同士を隔てる粒界相の厚みが保磁力と関 係する ${ }^{13)}$ 。すなわち， $T_{\mathrm{a}}=400 \sim 500^{\circ} \mathrm{C}$ の範囲では，粒界構 造の連続性や厚みの变化が起こり, 主相粒子間の磁気的結合 性が低下していき，保磁力が上昇すると推論できる．このこ とは，粒界拡散が行われた $\mathrm{Nd}-\mathrm{Fe}-\mathrm{B}$ 系焼結磁石についての 微細構造観察結果とも矛盾しない14)。一方, 静磁気的相互 作用も磁石粒子間の磁気的結合としては有力であり，長距離 的に影響が及ぶものと思われる。しかし， $500^{\circ} \mathrm{C}$ 程度の熱処 理では，磁石内部のマクロな構造に大きな変化はない。した がって, 静磁気的相互作用も粒子間の磁気的結合として影響 すると思われるが， $500^{\circ} \mathrm{C}$ 程度の熱処理によって大きく変化 するとは考えにくい，

次に, $T_{\mathrm{a}}=550^{\circ} \mathrm{C}$ 以上では, $V_{\text {soft }}$ の低下が起こり, 保磁 力は $T_{\mathrm{a}}=600^{\circ} \mathrm{C}$ 以上で急激な低下を示した．この 2 つ現 象を同時に説明できる機構は少なくとも 2 種類考えること ができる。

まず，一つ目のモデルは，ソフト粒子の体積分率に変化が ないと仮定し，ソフト粒子とハード粒子が再び磁気的に結合 したという考えである。つまり， $V_{\text {soft }}$ の低下はハード粒子 との磁気的結合によってもたらされたとすれば，同時に保磁 力の低下も起こるため，実験事実を説明できる。しかし， $V_{\text {soft }}$ が $T_{\mathrm{a}}=550^{\circ} \mathrm{C}$ で減少しはじめるのに対し, 保磁力は $T_{\mathrm{a}}$ $=600^{\circ} \mathrm{C}$ 程度から低下が起こり, 約 $50^{\circ} \mathrm{C}$ の違いがある.す なわち， $T_{\mathrm{a}}$ に対する $V_{\text {soft }}$ と保磁力の変化は類似しているが， $T_{\mathrm{a}}=550^{\circ} \mathrm{C}$ 以上ではそれぞれ異なる機構が関係していると考 える方が妥当である.

そこで，他に考えられる機構は，垂直方向の磁場中で強磁 場熱処理と磁場中冷却を行った際に形成された低保磁力化の 原因が， $T_{\mathrm{a}}=550^{\circ} \mathrm{C}$ 以上で弱まったとするモデルである．例 
えば，垂直方向に配向した微細な $\mathrm{Nd}_{2} \mathrm{Fe}_{14} \mathrm{~B}$ が再溶解するこ とや，粒界に生じた Nd リッチ粒界相の液相によって逆磁区 の核生成サイトが主相表面から除かれ，ソフト粒子がハード 化した，といったことなどを考えることができる.

なお， $800^{\circ} \mathrm{C}$ で熱処理を行った際に磁場を印加しなかった 参照試料でも, 保磁力の熱処理温度依存性について, Fig. 3 の結果とほとんど同じ傾向が得られた。また，一般的な $\mathrm{Nd}-\mathrm{Fe}-\mathrm{B}$ 系焼結磁石においても, 保磁力はある熱処理温度 で最大值をとり, Fig. 3 と類似した結果が得られる.すなわ ち, この節で考察した内容を用いると, 一般的な $\mathrm{Nd}-\mathrm{Fe}-\mathrm{B}$ 系焼結磁石においても同様に保磁力の熱処理温度依存性を矛 盾なく説明できると考えられる.

\section{4. まとめと今後の課題}

$\mathrm{Nd}-\mathrm{Fe}-\mathrm{B}$ 系焼結磁石を, $\mathrm{Nd}-\mathrm{Fe}-\mathrm{B}$ 系三元共晶温度以上の $800^{\circ} \mathrm{C}$ で強磁場中熱処理をした際の, 磁場方位依存性につい て調べた. 試料の配向方向に対して垂直磁場中で強磁場中熱 処理, 磁場中冷却を行うことで, 顕著な減磁曲線の角型性の 劣化を観測した．その試料について，SSA 法を用いて減磁 曲線の熱処理温度に対する変化を追跡した. その結果, 解析 したソフト領域の体積分率と保磁力の熱処理温度に対する振 る舞いから, $400^{\circ} \mathrm{C}$ から $500^{\circ} \mathrm{C}$ の比較的低温の範囲では, 磁 石粒子間の磁気的結合性が弱まることで, 保磁力が上昇する ことを示唆した. さらに, 垂直方向の強磁場中で熱処理を行

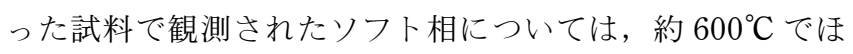
ぼ観測されなくなることがわかった.このことについて, 試 料の配向方向に対して垂直方向の強磁場中熱処理によって, 主相表面に形成された低保磁力化の原因が， $600^{\circ} \mathrm{C}$ 程度で消 失するとして考察した.

しかし, 強磁場熱処理と磁場中冷却を行った試料の微細構 造観察は現在進行中であり, いまのところ垂直方向の磁場中
で保磁力が低下した原因は不明である. 今後は強磁場中熱処 理が微細構造に及ぼす影響を明らかにすることを目的とし て, 微細構造観察の面から研究を進めていくことを計画して いる.

本研究は独新エネルギー・産業技術総合開発機構 (NEDO) 「希少金属材料代替プロジェクト, 希土類磁石向けジスプロ シウム使用量低減技術開発」の支援を受けて行われた。また 強磁場熱処理実験は, 東北大学金属材料研究所付属強磁場超 伝導材料研究センターで行われた.

\section{文献}

1) S. Hirosawa, Y. Matsuura, H. Yamamoto, S. Fujimura, M. Sagawa and H. Yamauchi: J. Appl. Phys. 59 (1986) 873-879.

2) K. Hirota, H. Nakamura, T. Minowa and M. Honshima: IEEE Trans. Magn. 42(2006) 2909-2911.

3) W. F. Li, T. Ohkubo and K. Hono: Acta Mater. 57 (2009) 13371346 .

4) W. F. Li, T. Ohkubo, T. Akiya, H. Kato and K. Hono: J. Mater. Res. 24 (2009) 414-420.

5) A. G. Popov, T. Z. Puzanova, V. S. Gaviko, D. Yu. Vasilenko and V. P. Vyatkin: Phys. Metal. Metall. 101(2006) 538-546.

6) F. Vial, F. Joly, E. Nevalainen, M. Sagawa, K. Hiraga and K. T. Park: J. Magn. Magn. Mater. 242-245(2002) 1329-1334.

7) T. Akiya, H. Kato, M. Sagawa, K. Koyama and T. Miyazaki: J. Magn. Soc. Jpn. 30 (2006) 447-454.

8) T. Akiya, H. Kato, M. Sagawa and K. Koyama: IOP Conf. Series: Mater. Sci. Eng. 1(2009) 012034-1-6.

9) P. Courtois, R. P. Bâthie and R. Tournier: J. Magn. Magn Mater. 153(1996) 224-230.

10) T. Akiya, F. Sato, Y. Une, M. Sagawa and H. Kato: J. Magn. Soc. Jpn. 34 (2010) 242-247.

11) X. Li, Y. Fautrelle and Z. Ren: Acta Mater. 55(2007) 13771386.

12) Y. Matsuura, S. Hirosawa, H. Yamamoto, S. Fujimura, M. Sagawa and K. Osamura: J. Appl. Phys. 24(1985) L635-637.

13) A. Sakuma, S. Tanigawa and M. Tokunaga: J. Magn. Magn. Mater. 84(1990) 52-58.

14) H. S. Amin, T. Ohkubo and K. Hono: J. Appl. Phys. 107 (2010) 09A745-1-3. 